\title{
Improving the project service performance of companies producing and marketing kitchen systems: Stage of survey and analysis of the space
}

\author{
Deniz Ayșe Yazicioğlu ${ }^{1, *}$, Alaattin Kanoğlu ${ }^{2}$ \\ 1Interior Architecture Department, Istanbul Technical University, Istanbul, Turkey \\ ${ }^{2}$ Architecture Department, Istanbul Technical University, Istanbul, Turkey
}

\section{A R T I C L E IN F O}

\section{Article history:}

Received 17 December 2016

Received in revised form

7 February 2017

Accepted 7 February 2017

\section{Keywords:}

Performance based design

Kitchen interior design

Space analysis

\begin{abstract}
A B S T R A C T
Scope and objective of this work has been determined as revealing problems which occur/may occur at the stage of "making survey and analysis of the kitchen space" which has an important role in the proper progressing of the project service period of the companies producing and marketing kitchen systems development of suggestions for solving the cited issues. As the methodology in line with this defined scope and objective, a web-based survey, with the attendance of all dealers of the company has been conducted with an eye to determine at the first stage how the designers of the company taken as sample model (having 60 dealers at national and international level) have carried out works as to making survey and analysis of the kitchen space. In the following stage, the results obtained from this survey conducted were evaluated and issues were identified. Subsequently, a literature search for solving these issues and interviews with relevant departments of the company were carried out and a standard form and registration system were created in line with the obtained data. At the final stage, this form and registration system were presented to the company's design teams and management departments by virtue of a web-based survey. Furthermore, it has been practically tested in a store deemed important by the company and has taken its final form by revising it in line with all the feedbacks received. The form and registration system developed in this study will be a part of the software model designed in the research project entitled "A Holistic Process Management Model for Increasing the Design Performance of Companies which Produce and Distribute Kitchen Systems".
\end{abstract}

(C) 2017 The Authors. Published by IASE. This is an open access article under the CC BY-NC-ND license (http://creativecommons.org/licenses/by-nc-nd/4.0/).

\section{Introduction}

Kitchen design performance indicator of companies producing and marketing kitchen systems, comprises numerous components such as satisfaction level of users as to the products and company's project service process; design, production and assembly times of the kitchen; aesthetic, quality and functional performance of the products as well as the total cost of the project and etc. Accordingly, issues such as proper progressing of the project service period and improvement of kitchen design performance in this context are very substantial for companies producing and marketing kitchen systems in the global competitive

\footnotetext{
* Corresponding Author.

Email Address: yazicioglude@itu.edu.tr (D. A. Yazicioğlu) https://doi.org/10.21833/ijaas.2017.02.023

2313-626X/@ 2017 The Authors. Published by IASE.

This is an open access article under the CC BY-NC-ND license

(http://creativecommons.org/licenses/by-nc-nd/4.0/)
}

environment of our day (Yazicioğlu and Kanoğlu, 2016a).

The design issue must be defined correctly for the success of the project service period of the companies producing and marketing kitchen systems. The problem, during the analysis thereof, needs to be separated into pieces, problems as to these pieces must be identified, the cited problems must be discussed with different perspectives and different solution proposals must be developed. To this end, boundaries of the design have to be known from the very beginning. Data as to changeable and non-changeable items must be carefully identified, and the technical conditions as well as quality requirements for the project should be fully described. It is very important that the data gathered during the preliminary preparation stage must be transferred to the designer without loss and can be accessed through the entire design team (Arditi and Günaydın, 1998; Yazicioğlu, 2012; Yazicioğlu and Kanoğlu, 2016b). 
The indoor project service process basically comprises five stages, disregarding the size and scope of the project. However the cited stages can sometimes continue by being intertwined with each other. In other words, various revisions can be made by going back to the design development process again due which has occurred in the application stage. Below is a brief definition as to what these five basic stages of the project service process are (Dodsworth, 2009; Piotrowski, 2011; Yazicioğlu, 2012; Yazicioğlu and Kanoğlu, 2016b):

- Stage I (Preliminary Preparation): This stage is the pre-design stage. A good interior design can only be possible if the preliminary preparation stage is concluded properly. Reaching precise and accurate data will greatly reduce the rate of error subsequently in the process and avoid time lost. The works to be done at this stage comprise mainly determining demands and requirements of the users, taking measurements, drawing plans and sections of the place and making space analysis.

- Stage II (Schematic Design): Schematic design is the stage in which ideas as to creativity start to be formed. The designer makes sketches and takes the main decisions regarding the project. These sketches roughly show the areas of circulation areas and activity as well as layouts of the equipments. Schematic design can also be supported through supplementary drawings such as balloon diagrams, matrices and tables describing the concept of the design (Piotrowski, 2011, Tangaz, 2006).

- Stage III (Development of The Design): In the stage of development of the design, all decisions with respect to the project have already been given. These decisions are reflected by virtue of the drawings of the plan, sections and application details in a way that the user can fathom. Furthermore, colorful perspective drawings describing the project are made. Lighting, heating, ventilation, clean and dirty water installation and all other mechanical drawings are completed. Moreover, the offer price for the entire project is determined (Piotrowski, 2011, Mitton, 2011).

- Stage IV (Preparation and Approval of Official Documents): At this stage drawings of the accepted project, all details as regards the project agreement including the job description, work schedule, price quotation file and etc. are confirmed by the customer. Furthermore, agreements are made with the subcontractors and official permits are obtained from the desired places. If necessary, consultants are assigned from experts such as engineers and architects (Piotrowski, 2011, Dodsworth, 2009).

- Stage V (Implementation): At this stage, the design is carried out in accordance with the concluded project and work schedule (Piotrowski, 2011).

These five basic stages of the existing project service process provided hereinabove have to be based on and evaluated systematically in order to identify all problems that may affect the design performance of the company producing and marketing kitchen systems taken as sample model and development of solution proposals. Elimination of the issues occurring/which may occur at each stage will provide superiority as to competition at the business level, will be able to support administrative decisions at the tactical level and increase productivity at the operational level and minimize time losses and conflicts (Yazicioğlu and Kanoğlu, 2016b).

One of the most important actors in kitchen design and implementation and one of the most important factors affecting the performance of the designer is that the preparation stage has to be done in a complete and correct manner. To this end, first and foremost priority is given to determination of problems which occur/may occur in works as to "determination of user demands and requirements" which is an important part of Stage I of project service period of companies that produce and market kitchen systems and to develop suggestions for solution of these problems. The cited work has been conducted by Yazicioğlu and Kanoğlu (2016a) presented in full detail to the article titled "Improving the Project Service Performance of Companies Producing and Marketing Kitchen Systems to Provide Sectoral Competitiveness"

Problems which occur/may occur in works as to "making survey and analysis of the space" which is also another important part of Stage I of project service period of companies that produce and market kitchen systems will be determined of and suggestions for solution of these problems will be developed.

\section{Purpose and methodology}

Scope and objective of the work has been determined as revealing problems which occur/may occur at the stage of "making survey and analysis of the kitchen space" which has an important role in the proper progressing of the project service period of the companies producing and marketing kitchen systems development of suggestions for solving the cited issues. As the methodology in line with this defined scope and objective, a web-based survey, with the attendance of all dealers of the company will be conducted in order to determine at the first stage the designers of the company taken as sample model (having 60 dealers at national and international level) have carried out works as to making survey and analysis of the kitchen space. In the following stage, the results obtained from this survey conducted will be evaluated and issues were identified. Subsequently, a literature search for solving these issues and interviews with relevant departments of the company will be carried out and a standard form and registration system will be created in line with the obtained data. At the final stage, this form and registration system will be presented to the company's design teams and 
management departments by virtue of a web-based survey. Furthermore, it will be practically tested in a store deemed important by the company and will take its final form by revising it in line with all the feedbacks received.

\section{Problems at the stage of survey and analysis of the kitchen space}

A web-based survey, with the attendance of all the designers of the company taken as sample model has been conducted in order to reveal problems which occur/may occur at the stage of making survey and analysis of the kitchen space. At the end of this study, the similarities of the answers given by the designers were brought together and the results in Table 1 were reached (Yazicioğlu and Kanoğlu, 2016b).

When the data in Table 1 is evaluated, it is observed that a systematic approach has been followed in the process of making survey and analyzing the kitchen space. It has also been found that an insufficient number of data was collected, in particular as regards the analysis of the space.

Table 1: Questions asked for determination of problems occurring at the stage of making survey and analysis of the kitchen space and the answers given by the designers to these questions

\begin{tabular}{l} 
Questions \\
\hline In order to create an archive \\
system for all of the projects you \\
have done, what information \\
must be recorded (user's name \\
and surname, tel-fax no. \\
residence address, Address \\
where assembly will be made \\
and etc.)?Please list.
\end{tabular}

Which measures of the place where the kitchen project will be applied do you take? Please list it in a complete way.

What would you pay attention to except for measuring the installation (clean water, dirty water, electricity, natural gas, etc.) in the kitchen? Please list.

What do you pay attention to except for measuring the outlet of the chimney in the kitchen? Please list.

If existing devices will be used in a new kitchen, what do you note as to them? Please list.

If the existing kitchen sink will be used in a new kitchen, what do you note about this sink? Please list.

Answers

- User's name and surname.

- User's Identity No.

- Communication contact details (telephone, postal address, residence address).

- Address where assembly will be made.

- Design style of the existing kitchen.

- User's profession.

- Color and cover types which the user likes, payment options, and product information.

- Survey, photos and visual project of the kitchen to be assembled.

- Measures of existing chimney location and hole, measurements of locations of the electricity, water, natural gas installation and central heater boiler.

- All dimensions of the kitchen and/or space, wall dimensions, ceiling height, column, beam, curtain wall, window, door dimensions, opening way of doors and windows.

- Device measurements.

- Measurements of present accessories to be utilized in the new kitchen.

- Depth and height relationship of the chimney with the beam.

- Places where the installation passes.

- Wall system (brick, concrete tunnel, gypsum board, insulation coating)

- Entry and exit locations to the space.

- If the installation is embedded in the wall and if it is intact.

- Locations of the socket, switch and central heater.

- Materials and colors of the countertop and floor.

- Where will the free space to be used during shipment be?

- If the walls are out of square or not.

- Openings and directions of windows and doors.

- If it is possible to make a compatible design possible to install with standard modules if the user does not wish to make any modifications, assuming that the entire installation will remain in its same place.

- By which minor intervention restoration can be done if there is a need to make restoration.

- Height and other obstacles on the ground.

- In case of open kitchen if there is height difference with the place where the kitchen is associated.

- If the user wishes to make restoration, conditions of carrying the installation within the existing structure.

- If each house is its own chimney.

- Chimney's relation with cooker, hood, natural gas.

- If the chimney works or not, its suction power, its connection with other houses, if smell comes from the chimney of neighboring houses.

- Conditions for changing the place of the chimney if necessary.

- If they are solo or built-in.

- Device measurements.

- Since when they are used.

- Brands and codes of devices.

- Visual properties of devices.

- If the device is defective, why is it defective?

- How the needs of ventilation of devices needing ventilation are met.

- Dimensions of the kitchen sink, its model and if dropper location and bottom connections are missing or not.

- If any damage occurred while disassembling from the old countertop and if all connection parts and its insulation are in good condition.

- If the existing kitchen sink is suitable for the new closet and countertop to be made.

- If the mounting type is under-bench or over-bench.

- Its brand and model. 

used in a new kitchen, what do
you note about this armature? Please list.

- Width and height of the armature.

- Connection diameter in the new kitchen sink.

- In cases when the kitchen sink will be in front of the window, if the armature will prevent the window wing from opening or not.

- If the armature itself and all its connections are intact and if there will be a working problem in the place to be used.

- From the kitchen sink or from the wall.

- If it is suitable for the new kitchen sink.

- Dining table and chairs.

- Upper cabinets.

Which furniture would your users usually like to keep in your current kitchen? Please list.

Which method do you use to understand how the loadbearing system of the place where the kitchen project will be built is? Please explain.

What do you note about the load-bearing system of the place where the kitchen project will be made? Please list.

What else do you note about the space after you have taken measure in the house where the kitchen project will be done? (Interior design style, if the kitchen has a balcony of not, if the kitchen is an open or closed space, etc.)? Please list.

Do you need to take photos of the space where the kitchen design will be done?

What do you take photos of the space where the kitchen design will be done? Please list.
- By reviewing the static project of the existing structure, or by scraping the plaster on the wall and seeing if it is concrete or brick, gas concrete and etc.

- By getting information from the site manager if the building is new and y getting information from the former property owner if the building is old.

- By having it controlled by the master will do the construction.

- Dimensions of the load-bearing system.

- Type of load-bearing system and when it was made.

- Material of the load-bearing system.

- Locations of the load-bearing system in the space.

- If the wall needs to be strengthened to place the cabinets on it.

- The location of the kitchen in the house.

- If the kitchen sees the sun.

- If the existing kitchen is an open kitchen, what kind of top closet can be used if it is an open kitchen?

- Floor covering material and color.

- The style of the furniture in the place the kitchen is together with if the kitchen is open.

- The area of the place the kitchen is together with if the kitchen is open.

- If island kitchen can be made or not.

- Door and window opening directions.

- If the balcony can be joined to the kitchen and if the beam will come out if the balcony can be joined to the kitchen.

- If the kitchen can be joined with a space adjacent to the kitchen.

- If there are walls to be demolished, opened or put up and closed.

- If there is a dining table in the kitchen.

- Which rooms are adjacent to the kitchen?

- Yes

- No

- The photo of the kitchen from the inside corners and the facade to which it is directed

- Floor, ceiling and walls.

- Locations of plumbing, heater cores, natural gas and central heater boiler.

- Different views of walls from every angle on which installation will be made.

- The photo of the kitchen from the door showing all the walls of the kitchen.

- The balcony, if any, and the place the kitchen is together with if the kitchen is open.

- The window and the view seen from the window.

- Kitchen entrance door.

- Columns and beams.

\section{Elimination of problems at the stage of survey and analysis of the kitchen space}

The problems that occurs/may occur at the stage of making survey and analysis of the kitchen space were determined as not usage of a standard set of questions in which a systematic approach is followed, insufficiency of data collected as to the analysis of the space and therefore not fulfillment of "full completion of the preliminary preparation stage". In order to overcome these problems, it is necessary to create a standard form and a registration system that designers will use during making the survey and analysis of the space. To this end, firstly a literature search was conducted to determine how the form and registration system should be created (Baden-Powell, 2005; Beamish et al., 2013; Beazley, 1999; Bouknight, 2004; Child, 1914; Calley, 2007; Cerver, 2006; Goldbeck, 1994;
Dodsworth, 2009; Edic and Edic, 1999; Jankowski, 2001; King, 2006; Lester and McGuerty, 2010; Lovett, 2003; Panero and Zelnik, 1979; Pheasant, 1996; Piotrowski, 2011; Rand and Perchuk, 1991; Roney, 2008; Spurling, 2010; Stephenson and Stephenson, 1960; Sweet, 2003; Yazicioğlu, 2010; Ward, 1974). It was decided that the form and registration system should consist of three main parts in line with the data obtained as a result of these searches. The cited parts and their purpose of usage are as follows:

- Part I: This part will be created for the purpose of collecting data about user information, devices, equipment inventory, armatures and the furniture which use of which is desired to be continued in the new kitchen.

- Part II: This part will include questions to be asked if modifications about the space are desired. 
- Part III: This part will like a check list showing what to check before leaving the space.

While Part I of the creation of the form and registration system as to making the survey and analysis of the kitchen space care was taken to ensure that they were created in a manner to allow the collection of data as quickly and as completely as possible registration system. Three different form options created to this end were tried in practice in one of the stores which the sample model considered important and the form which was determined to be most functional in line with the obtained results was revised and Part I of the registration system was completed (Table 2).

Table 2: The form and registration system as to making the survey and analysis of the kitchen space-Part I

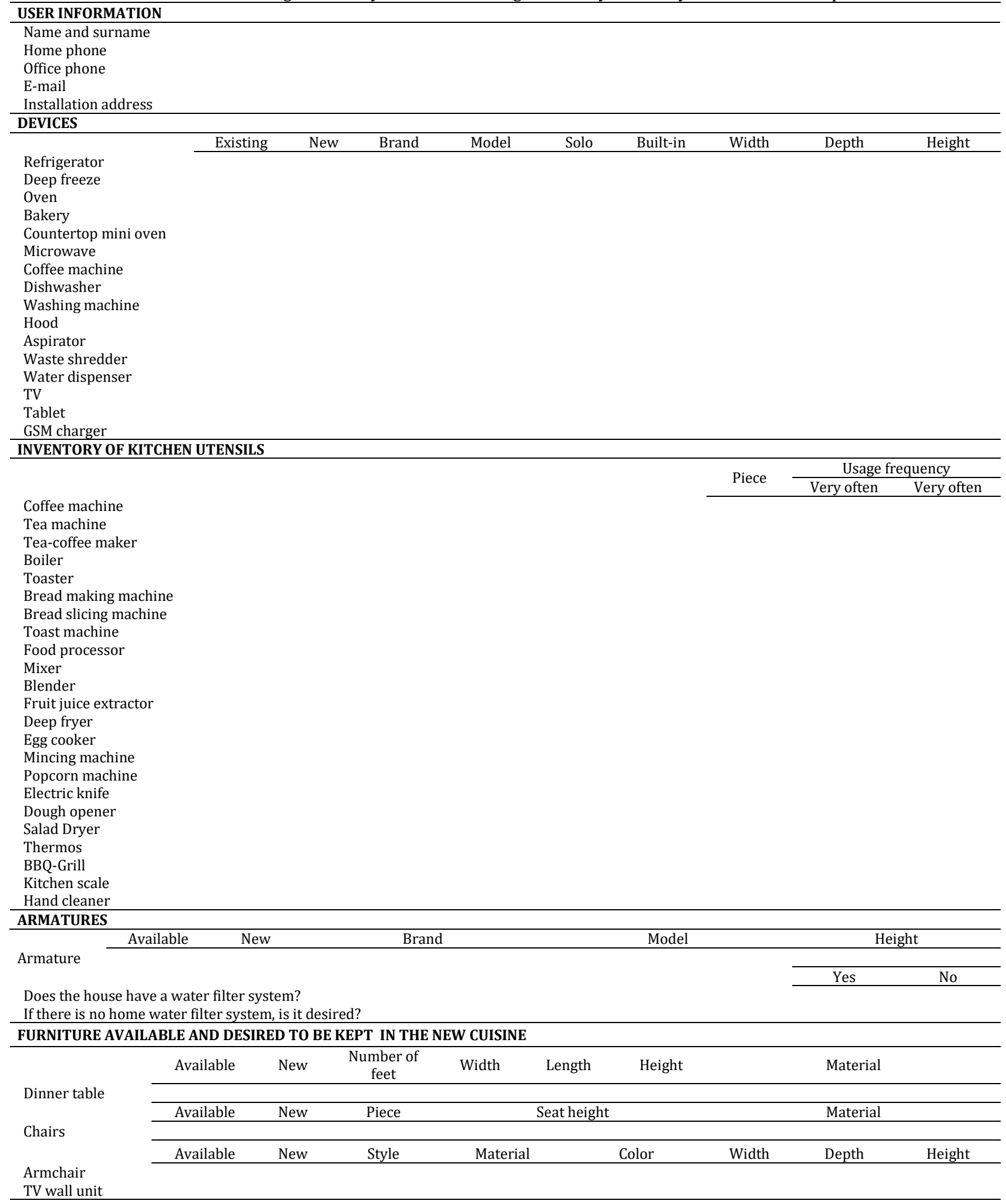

In-depth interviews with the company design and modification teams were conducted in addition to the literature researches for creation of "questions that should be asked if modification as to the space is 
desired" which is Part II of the form and registration system. Then, the obtained data were compiled and similar ones were eliminated and it was decided that the question set should be as follows. The answers to these questions will be either "Yes", "No" or "No idea":

- Do you desire to enlarge the kitchen?

- Do you desire to combine the kitchen with another space?

- If the kitchen is open, do you desire it to be converted into a closed kitchen?

- If there is a balcony, is it desired to combine it with the kitchen?

- If there will be a door in the new kitchen, do you desire to change the dimensions of the existing door?

- If there will be a door in the new kitchen, is it desired to change the location of the existing door?

- If there is more than one door in the current kitchen, is it desired to close some of the doors in the new kitchen?

- If there will be a door in the new kitchen is it desired to change the opening direction of the existing door?

- Is going to be opened, do you desire to change the form of the existing door (Sliding, one-way opening, two-way opening, etc.)?

- Do you desire to change the opening way of the window (sliding, guillotine etc.)?

- Is a service window desired?

- Do you desire to renew the natural gas installations?

- Do you desire to renew your clean and dirty water system?

- Do you desire to renew your electrical installation?

- Is the ventilation system desired to be renewed?

- Do you desire to renew your heating system?

- If there is no suspended ceiling, is it desired to be done?

- Do you desire to remove the suspended ceiling if there is one?

- If there is a suspended ceiling, is it desired to be renewed?

- If there is no drywall, is it desired to be made?

- If there is a drywall, is it desired to be removed?

- If there is a drywall, is it desired to be renovated?

- Is the floor covering desired to be renovated?

- Do you desire to renew the wall surface material?

- Is it necessary to renew the countertop material?

By asking these questions about the determination of the planned alterations planned for the space, the designer will be able to communicate with the restoration teams in advance of the prepreparation stage of the project and make the purchases of necessary materials and minimize the unforeseen situations that could disturb the work program in the application stage. And this will ensure the delivery of the work in a timely and complete manner.
In-depth interviews with the company design and modification teams were conducted in addition to the literature researches for determination of "issued to be checked prior to leaving the space "which is Part II of the form and registration system. Then, the obtained data were compiled and similar ones were eliminated and a check list containing the items in Table 3 was created.

It will be possible to ensure that all the details as to taking the dimensions of the space are checked again very quickly, all necessary photos are taken during the designing stage and determine the basic problems that may cause the modification and assembly team to encounter unexpected situations during the application stage thanks to the check-list including the items in Table 3.

\section{Conclusions}

It will be possible to receive the information necessary to make survey and analysis of the kitchen space thanks to the form and registration system created within the scope of the study in a complete and fast manner. This will enable the project process to progress more accurately. Furthermore, these data will be able to be converted into a set of information (a database) from which various statistical results can be obtained inasmuch as they are collected by each and every designer using a standardized form and registration system. Statistical results as to finding out mostly which restoration are made in the space, what kind of equipment and furniture are desired to be maintained in the kitchen, in which settlement areas kitchen sales are performed mostly and project services are given mostly for which kitchens dimensions and etc. will be able to be reported and these reports will be able to be used by the related departments of the company (sales, marketing, R\&D and etc.) to improve kitchen design performance thanks to this database.

The form and registration system developed in this study will be a part of the software model designed in the research project entitled "A Holistic Process Management Model for Increasing the Design Performance of Companies which Produce and Distribute Kitchen Systems".

\section{Acknowledgement}

This article was prepared by using data belonging to a certain phase of the research project titled "A Holistic Process Management Model for Increasing the Design Performance of Companies which Produce and Distribute Kitchen Systems". As such, we would like to express our sincere thanks and appreciation both to Scientific Research Projects Department of the Istanbul Technical University and Doğtaş-Kelebek Mobilya Sanayi ve Tic. A.Ş. which have kindly supported the cited research projects. 
Table 3: The form and registration system as to making the survey and analysis of the kitchen space-Part III

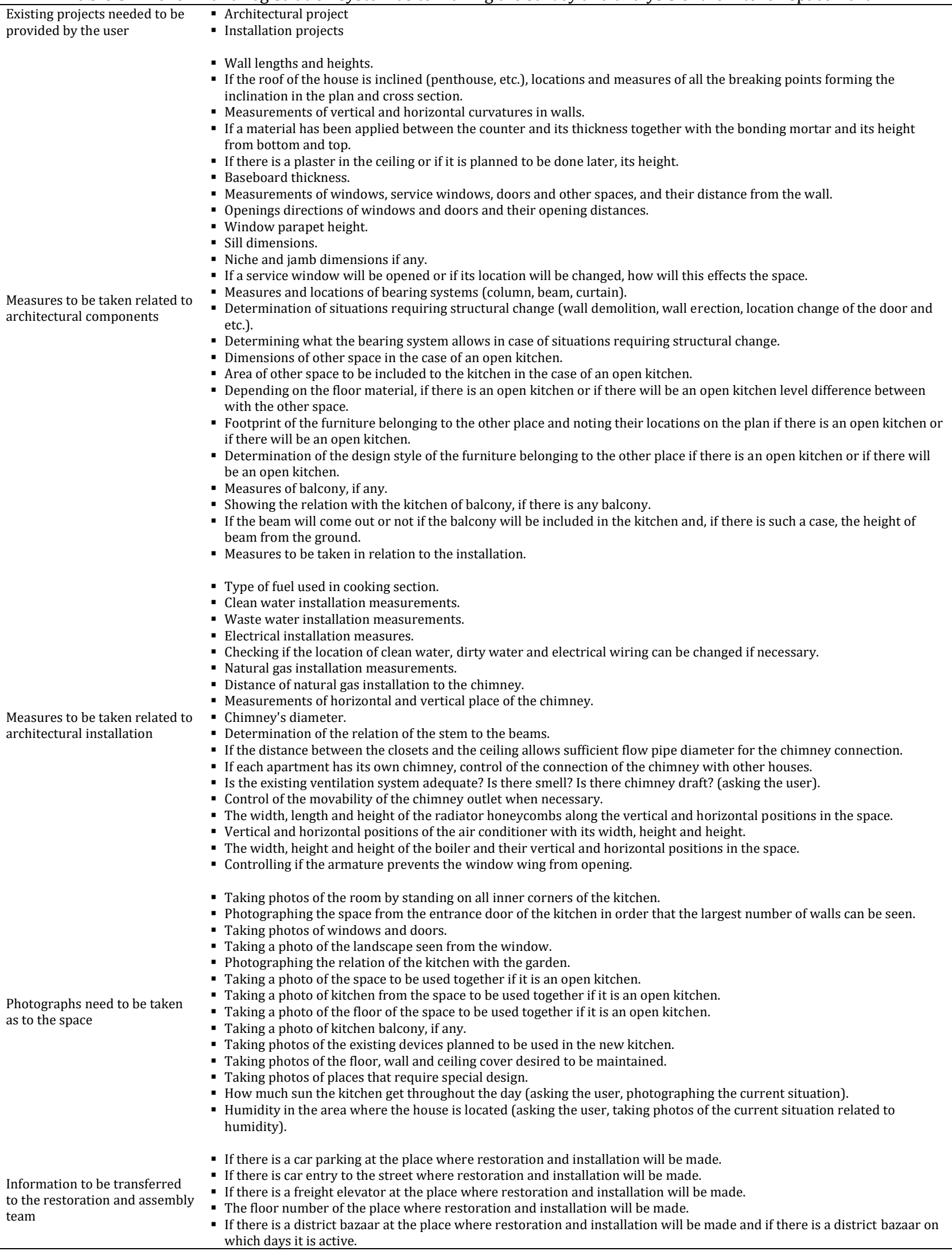

\section{References}

Arditi D and Günaydın HM (1998). Factors that affect process quality in the life cycle of building projects. Journal of Construction Engineering and Management, 124(3): 194-203.

Baden-Powell C (2005). Architect's pocket book of kitchen design. Routledge, Abingdon, UK.
Beamish J, Parrott KR, Emmel J, and Peterson MJ (2013). Kitchen planning-guidelines, code, standarts. John Wiley \& Sons, Inc., Hoboken, New Jersey, USA.

Beazley M (1999). The new kitchen planner. Octopus Publishing Group Ltd., London, UK.

Bouknight JK (2004). New kitchen idea book. Taunton Press, U.S. Kesseböhmer, Germany. 
Calley E (2007). Kitchens: Creating beautiful rooms from start to finish. House Beautiful Design \& Decorate, Hearst Corporatin, USA.

Cerver FA (2006). Ultimate kitchen design. The Neues Publishing Company, USA.

Child GB (1914). The efficient kitchen: definite directions for the planning, arranging and equipping of the modern labor-saving kitchen. McBridge, Nast and Company, New York, USA.

Dodsworth S (2009). The Fundamentals of Interior Design. Ava Publishing, Worthing, UK.

Edic M and Edic R (1999). Kitchens that work: the practical guide to creating a great kitchen. The Tauton Press, Newtown, USA.

Goldbeck D (1994). Smart kitchen: how to create a comfortable, safe, energy-efficient, and environment-friendly workspace. $2^{\text {nd }}$ Edition, Ceres Press, Boston, USA.

Jankowski W (2001). Modern kitchen workbook: a design guide for planning a modern kitchen. Rockport Publishers, Beverly, USA.

King HT (2006). Design ideas for home decorating. Creative Homeowner Press, Emeryville, USA.

Lester K and McGuerty D (2010). The complete guide to contracting your home. $4^{\text {th }}$ Edition, F+W Media, Inc, Blue Ash, USA.

Lovett SM (2003). The new smart approach to kitchen design. Creative Homeowner, USA.

Mitton M (2011). Residential interior design: A guide to planning spaces. John Wiley \& Sons, New Jersey, USA.

Panero J and Zelnik M (1979). Human dimension and interior space: a source book of design reference standards. WatsonGuptill Publications, New York, USA.

Pheasant S (1996). Body space, anthropometry, ergonomics, design. Taylor \& Francis, London, UK.
Piotrowski CM (2011). Becoming an interior designer: a guide to careers in design. John Wiley \& Sons Inc., Hoboken, New Jersey, USA.

Rand E and Perchuk F (1991). The complete book of kitchen design. Consumer Reports Books, New York, USA.

Roney C (2008). The nest home design handbook: simple ways to decorate. Organize and Personalize Your Place, Clarkson Potter, New York, USA.

Spurling A (2010). The home hub [Consumer Tech Kitchens]. Engineering \& Technology, 5(9): 28-29.

Stephenson H and Stephenson L (1960). Interior design. Studio Vista Limited, London, UK

Sweet F (2003). Kitchen essentials. Ryland Peters and Small Inc., New York, USA.

Tangaz T (2006). Interior design course: principles, practices, and techniques for the aspiring designer. Thames \& Hudson, Barron's Educational Series, USA.

Ward JS (1974). Critical ergonomics factors in domestic kitchen design. Ergonomics, 17(2): 233-240.

Yazicioğlu DA (2010). Mutfak tasarim süreci: analiz-kararplanlama. Literatur Yayincilik, İstanbul, Turkey.

Yazicioğlu DA (2012). Konutta İç Mekan Tasarımı. Literatur Yayincilik, İstanbul, Turkey.

Yazicioğlu DA and Kanoğlu A (2016a). Improving the project service performance of companies producing and marketing kitchen systems to provide sectoral competitiveness. International Journal of Sciences: Basic and Applied Research, 26(2): 18-27.

Yazicioğlu DA and Kanoğlu A (2016b). An integrated process management model as regards design performance improvement of companies producing and marketing kitchen systems. https://doi.org/10.13140/RG.2.2.11470.87369 